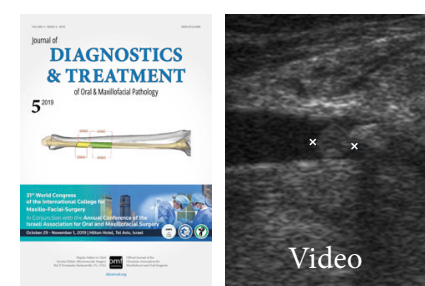

Ultrasound | Salivary Glands: Case Report + Video

\title{
Effectiveness of Ultrasound in Verification of the Mucus Plugs and Sialoliths of the Wharton`s Duct
}

\author{
Olha S. Cherniak and levgen I. Fesenkob, *
}

\section{S U M M A R Y / I N T R O D U C T I O N \\ The pathological changes in 467 submandibular glands were identified both endoscopically and radiographically, and endoscopic findings showed three types: calculus (91 percent), mucus plug (3 percent), and stenosis (6 percent). ${ }^{1}$ \\ -Yu Chuangqi et al, 2013 \\ China}

Mucus plugs ${ }^{1,2}$ (synonyms: mucous plugs ${ }^{3}$, mucin plugs $^{4}$, fibromucinous plugs $^{5,6}$ and mucosal plugs ${ }^{7}$ ) and sialoliths (synonyms: salivary stones, salivary calculi ${ }^{1}$, and concrements ${ }^{8,9}$ ) belong to the one of the common causes of the obstructive salivary gland disease (synonyms: obstructive sialadenitis ${ }^{10}$ and obstructive sialadenopathy ${ }^{8}$ ). Among other etiologies of obstructive sialadenitis are: foreign bodies, inflammation, kinks, strictures, anatomic malformations, polyps or even tumors. ${ }^{11}$ Those causes are found in different percentages. The radiographic investigation e.g. X-ray and computed tomography (CT) are very useful in detection of the salivary stones. Nevertheless, as approximately $80-90$ percent of the sialoliths are opaque on a standard review $\mathrm{X}$-ray and CT, and in 10-20\% radiolucent. ${ }^{12,13}$ But these methods are not useful in the detection of mucus plugs due to the non-contrast features of the last. There are a lot of studies which described ultrasound features of the sialoliths. ${ }^{14,15}$ Also, there are some studies that demonstrate endoscopic view of the mucosal plugs in a ductal system ${ }^{1,7,16}$ and in some cases the authors during sialendoscopy noted the floating mucous plugs. ${ }^{17}$ But we cannot find articles in PubMed which demonstrate ultrasound and clinical appearance of the obstructive salivary gland disease caused by sialoliths with mucus plugs simultaneously.

The purpose of our article is to describe a first and precise description of ultrasound pattern of the mucus plugs comparing with sialolith and their clinical presentation after removal. We report the consecutive gray scale and color Doppler sonograms with a supplemental video.

${ }^{a}$ Head, Department of Ultrasound, Regional Diagnostic Center, Kyiv Regional Clinical Hospital, Kyiv, Ukraine.

${ }^{\mathrm{b}}$ Oral Surgeon, Center of Maxillofacial Surgery, Kyiv Regional Clinical Hospital, Kyiv, Ukraine (place of work at moment of article preparing).

$\mathrm{PhD}$, Assistant Professor. Department of Oral \& Maxillofacial Surgery, Private Higher Educational Establishment "Kyiv Medical University", Kyiv, Ukraine.

* Corresponding author address: 7 Antona Tsedika Street, Kyiv 02000, Ukraine.

Department of Oral \& Maxillofacial Surgery, Private Higher Educational Establishment "Kyiv Medical University"

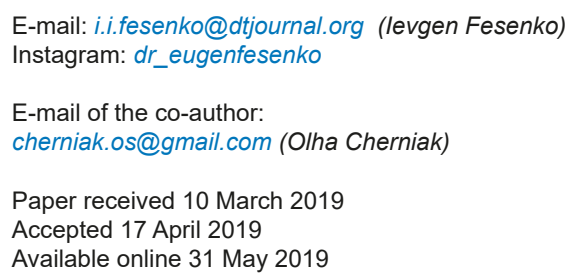

E-mail of the co-author: cherniak.os@gmail.com (Olha Cherniak)

Paper received 10 March 2019

Accepted 17 April 2019

Available online 31 May 2019

https://dx.doi.org/10.23999/j.dtomp.2019.5.3

(C) 2019 OMF Publishing, LLC. This is an open access article under the CC BY license (http://creativecommons.org/licenses/by-nc/4.0/). 


\section{CASE}

A 32-year-old woman was seen in Maxillofacial Surgery Center of the Kyiv Regional Clinical Hospital because of swelling in right submandibular and sublingual area during last days. The salivary colic (synonyms: postprandial salivary colic ${ }^{18}$, spasmodic pain during eating ${ }^{19}$ and meal time syndrome ${ }^{6}$ ) began to disturb the patient at the same time as the appearance of edema. An intraoral examination showed severe swelling of the mucosa in the right sublingual area with its significant erythema and a local necrosis (Fig 1). During massage of the right submandibular gland no milking exudate or saliva was present from the duct's orifice. Bimanual palpation of the right submandibular gland was painful to the patient and also indicated us the enlargement of the gland.

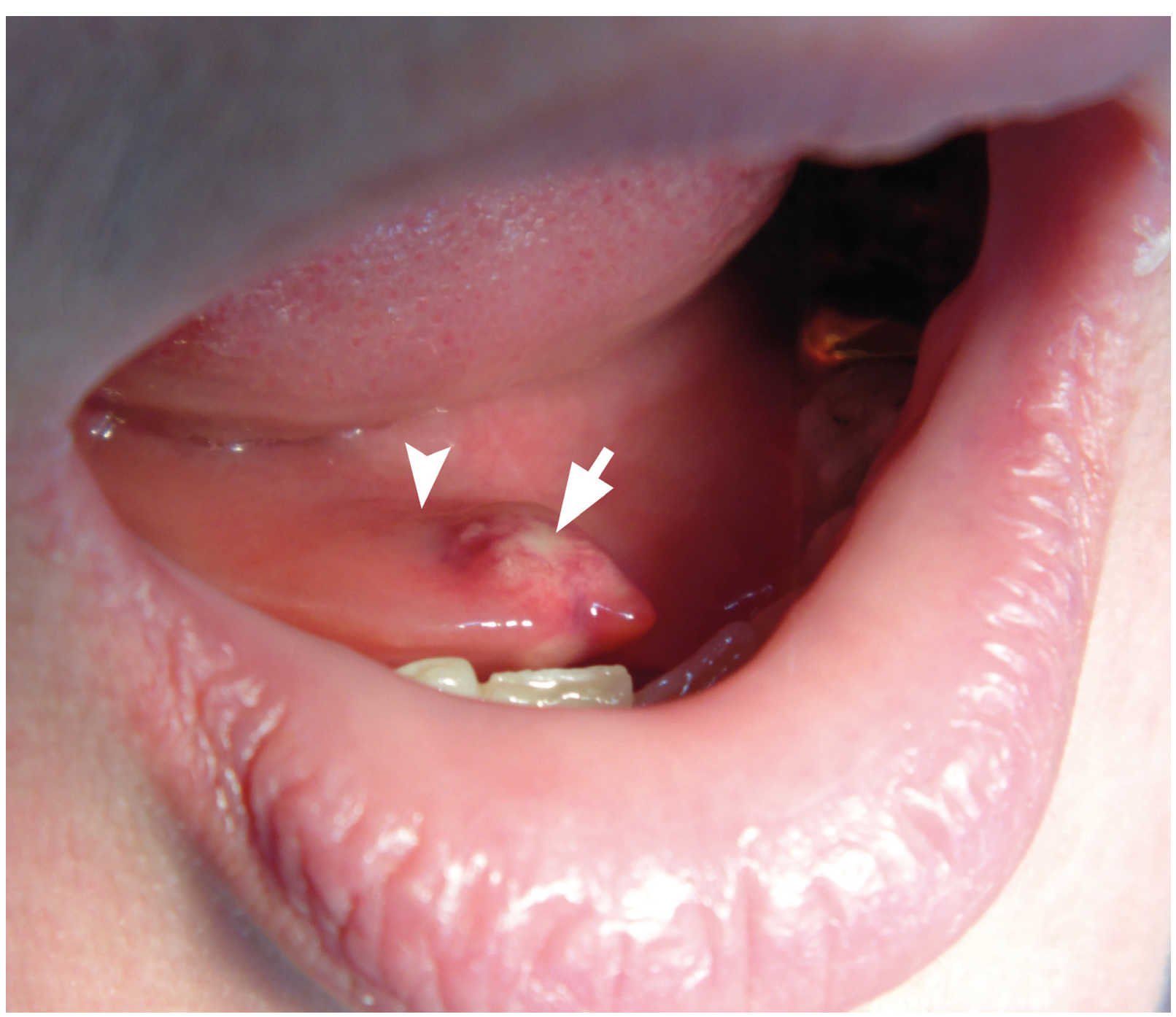

FIGURE 1. Intraoral view before ultrasound and treatment. Note an erythema and swelling (arrowhead) in the right sublingual area. Necrosis of the mucosa is indicated by arrow.

Ultrasound (US) investigation was performed with 12-3 MHz linear transducer (synonym: linear probe $^{14}$ ) (model HD11 XE, Philips). US in the right submandibular position showed the two-times enlarged right submandibular gland comparing with a contralateral organ (Fig 2). 

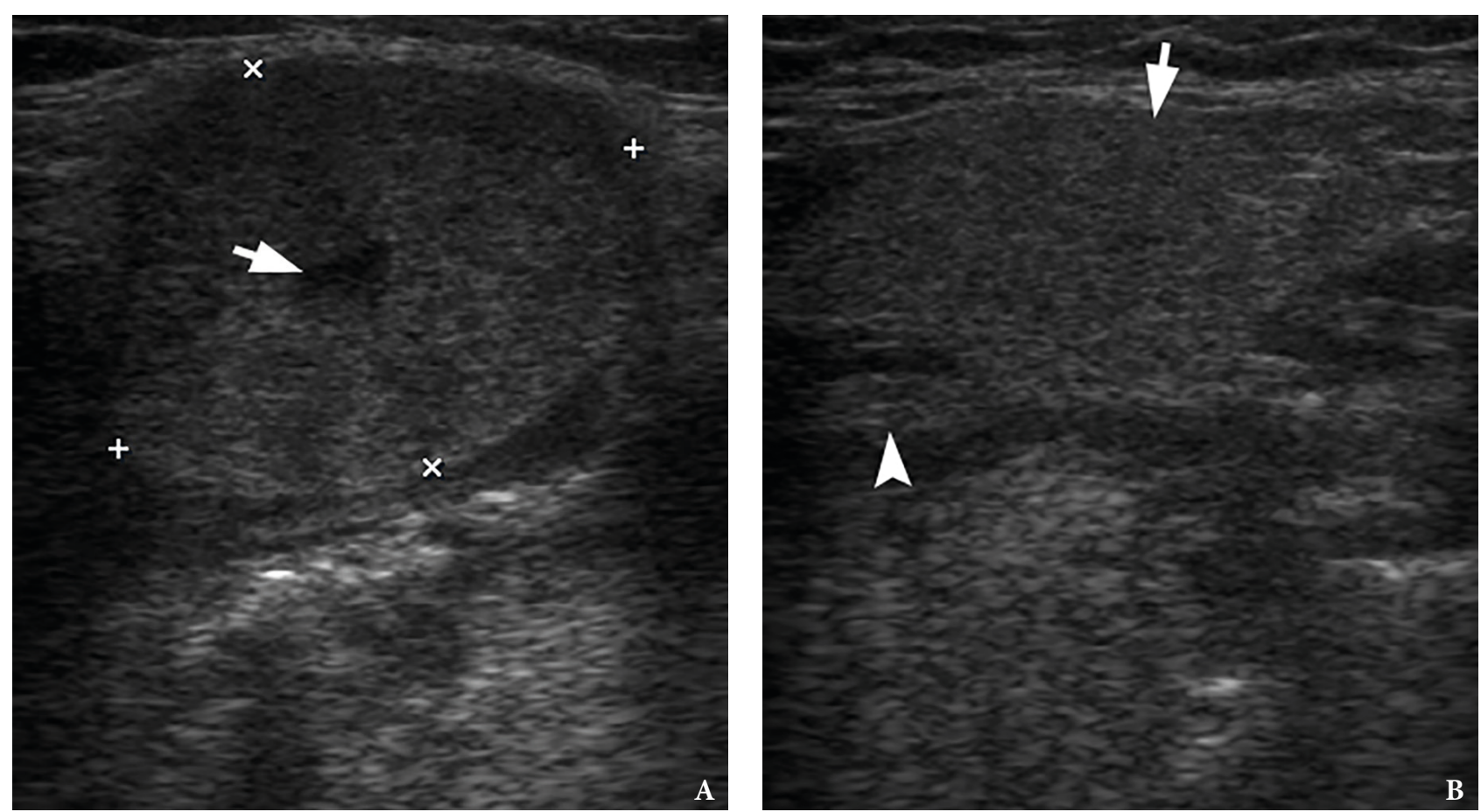

FIGURE 2. Comparison of the longitudinal gray scale sonograms of a right obstructed and inflamed submandibular gland (A) with a left nonsymptomatic gland (B). At image $\mathbf{A}$, the gland is indicated by ' + ' and ' $x$ ' calipers. The gland is enlarged in size almost twice and has a rounded form. Note a dilatation of the intraglandular duct (arrow). At image $\mathbf{B}$, the superficial (larger) lobe of the left nonsymptomatic gland is lying within the digastric triangle $\mathrm{e}^{19}$ and is indicated by arrow, the deep (smaller) lobe - by arrowhead.

In a longitudinal transducer's position the color Doppler US showed a striking increase of intraparenchymal vascularity (Fig 3) of the right obstructed gland. Gray scale ultrasound in the middle portion of the right Wharton's duct showed a hyperechogenic (synonym: hyperechoic) semilunar formation $0.43 \mathrm{~cm}$ in longitudinal size with artifact of 'clean' acoustic shadowing behind (Fig 4B). Posteriorly to the hyperechoic semilunar body in the duct, the US shows an isoechoic, round shape formation without acoustic shadowing. Its size reached $0.42 \mathrm{~cm}$ (Fig 4C). The Video (Supplemental Video Content) clearly demonstrates how significantly the whole Wharton's duct is dilated and its maximum width reached $0.5 \mathrm{~cm}$ at the posterior part. Video is available in the page of the full-text article on dtjournal.org and in the YouTube channel 'Videos DTJournal', available at https://youtu.be/ NF5MY6OW3BQ. Total video's duration: $10 \mathrm{sec}$. The duct was filled with anechoic fluid (supposedly suppurated saliva) (Fig 5).
A surgery was performed under local anesthesia (right inferior alveolar nerve block using $1.4 \mathrm{ml}$ Ultracain D-S forte, Frankfurt, Aventis Pharma Deutschland $\mathrm{GmbH}$ ) after suturing of the proximal part of the duct (to prevent displacement of the sialoliths and plugs posteriorly during surgery). A $1.0 \mathrm{~cm}$ incision was made above the swelled duct in the right sublingual area. The operation resulted in evacuation of the suppurated saliva in amount of approximately $5.0 \mathrm{ml}$ (Fig 6) with spontaneous emergence of the sialolith with several mucus plugs. An oval yellow sialolith was measured to be $0.5 \times 0.3 \mathrm{~cm}$ (Fig 7), what proved its preoperative measurement with ultrasound. Three pinky mucus plugs were $0.4 \times 0.4 \mathrm{~cm}, 0.15 \times$ $2.5 \mathrm{~cm}$, and $0.2 \times 0.25 \mathrm{~cm}$ in size. Special feature of the mucus plugs was its buttery consistency. That was proved by palpation (they are easily crushed) and even upon the contact with some surface (the plugs leave smudged trace).

The patient immediately felt relief after surgery. No postoperative complications were noted. 

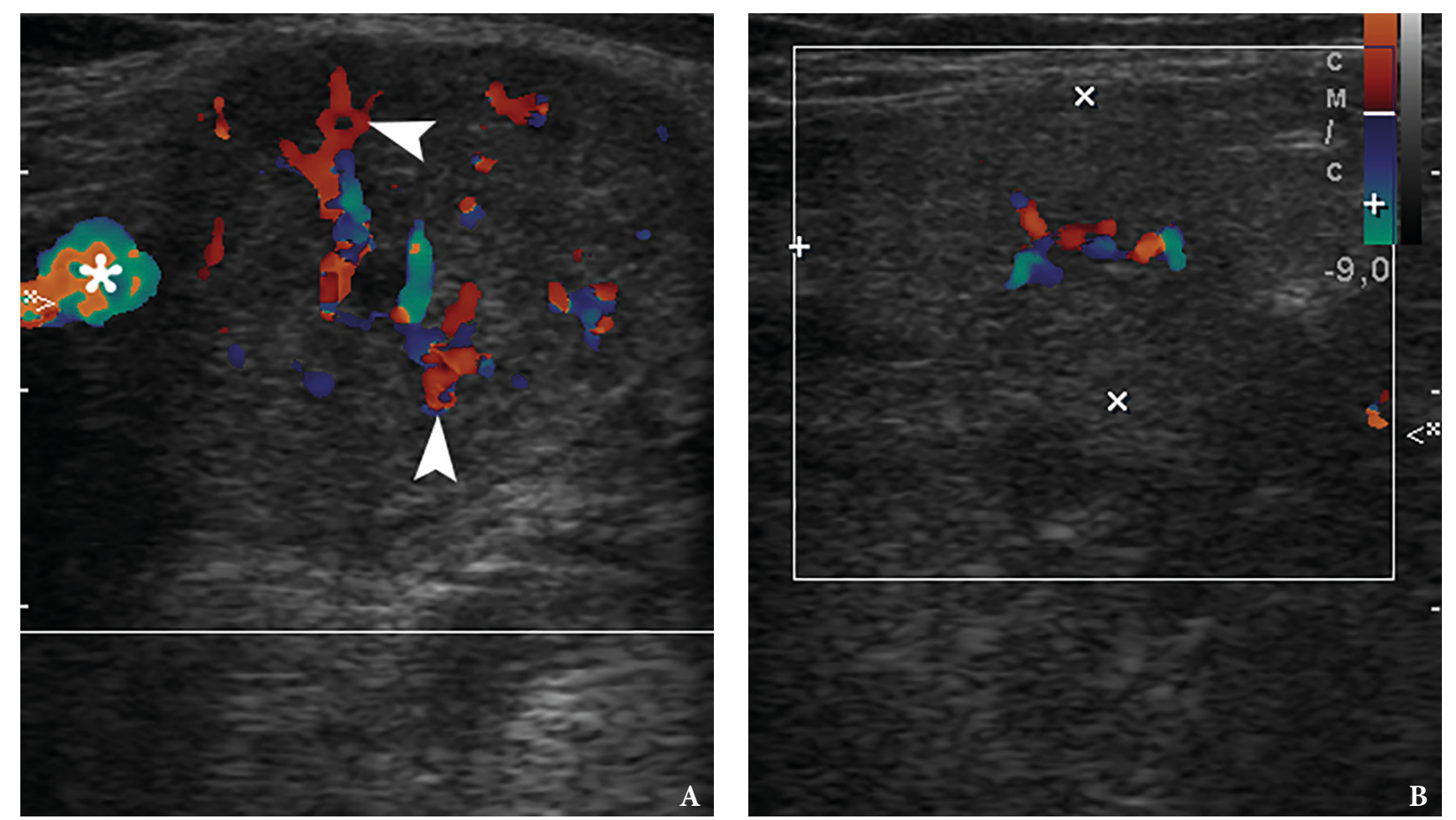

FIGURE 3. Longitudinal color Doppler ultrasound: Right inflamed submandibular gland (A) and left healthy submandibular gland (B). Comparing with a nonsymptomatic gland (B) (is indicated by 't' and ' $x$ ' calipers), the obstructed gland $(\mathbf{A})$ is enlarged in two times. A striking increase of intraparenchymal vascularity (arrowheads) of the right gland is noted. Facial vessel is indicated by asterisk at image $\mathbf{A}$.

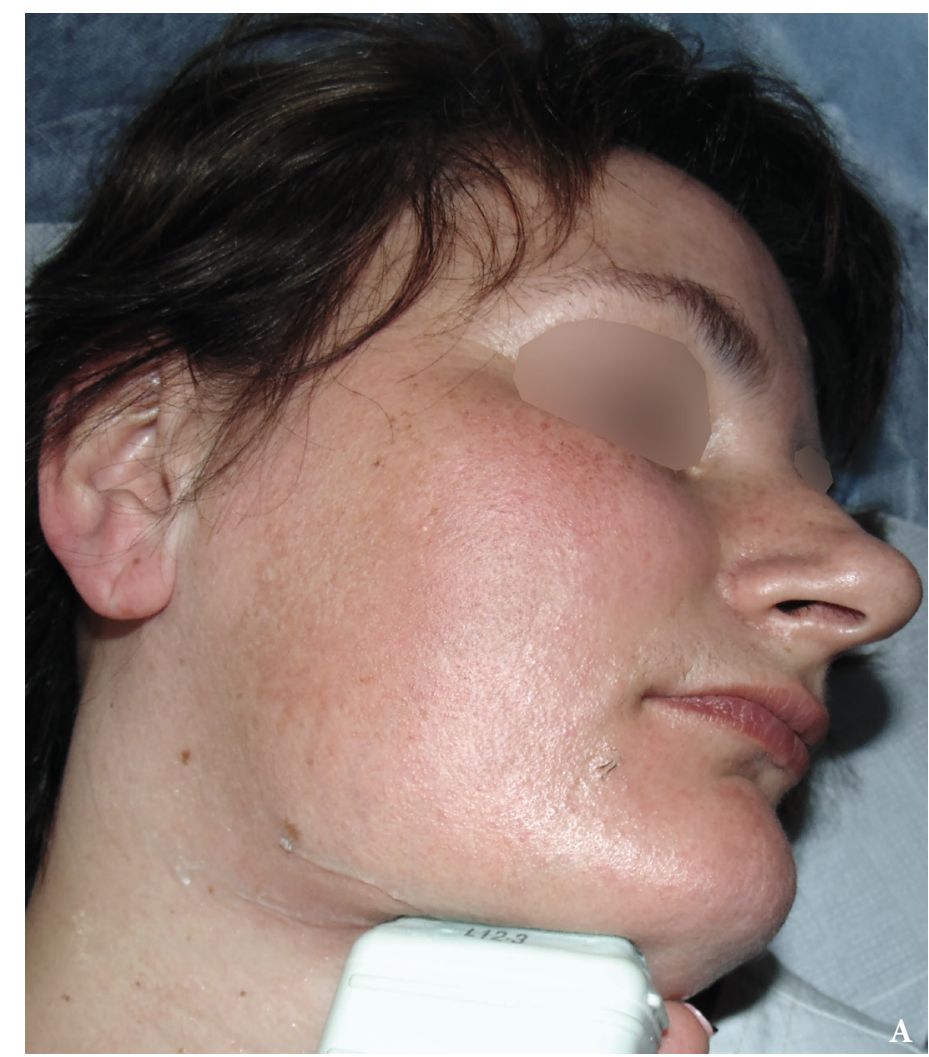

FIGURE 4. Position of the linear transducer is seen at image $\mathbf{A}$. (Fig 4 continued on next page.) 

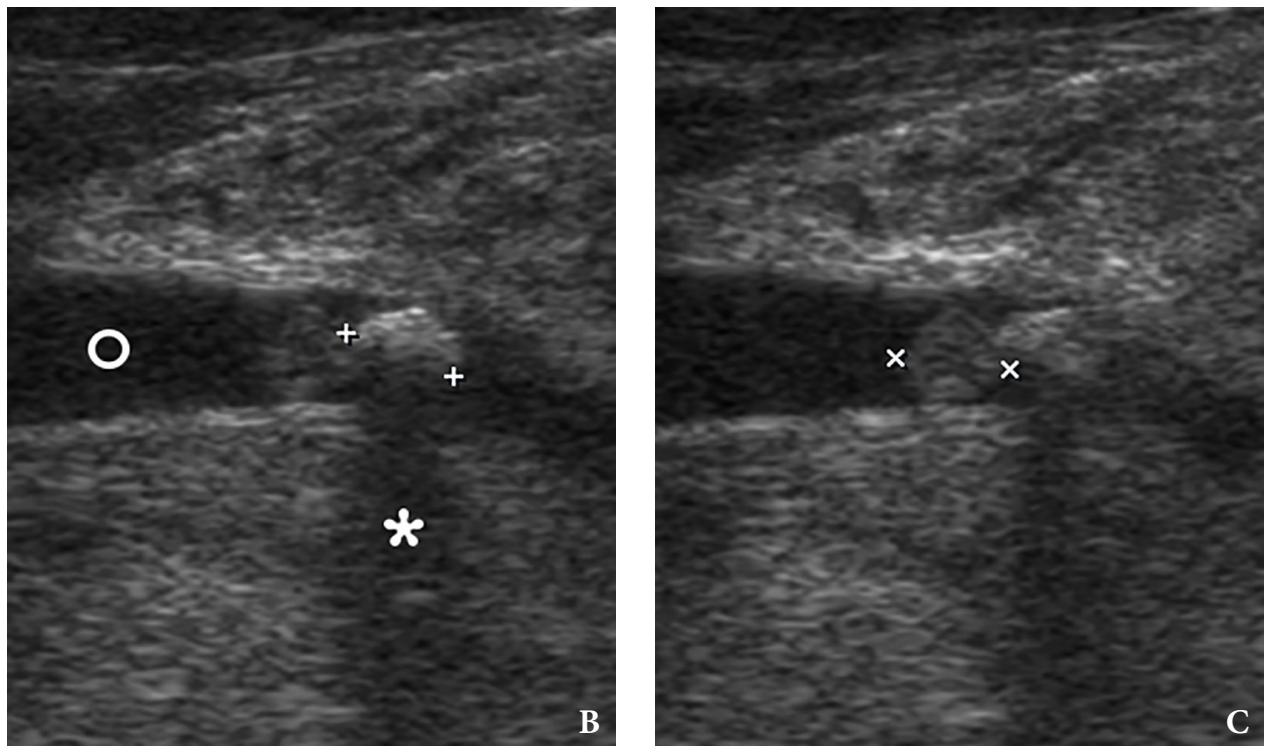

FIGURE 4 (cont'd). Gray scale ultrasound images (B, C) have been obtained in that position (in the projection of the middle part of the right Wharton 's duct). At image $\mathbf{B}$, a sialolith is indicated by ' + ' calipers and its longitudinal size is $0.43 \mathrm{~cm}$. A stone has a hyperechoic semilunar form with artifact of acoustic shadowing behind (asterisk). Circle indicates a lumen of dilated duct filled with anechoic fluid. At image $\mathbf{C}$, a mucus plug is indicated by ' $x$ ' calipers and its longitudinal size reached $0.42 \mathrm{~cm}$. A plug is isoechoic, round shape formation without acoustic shadowing.
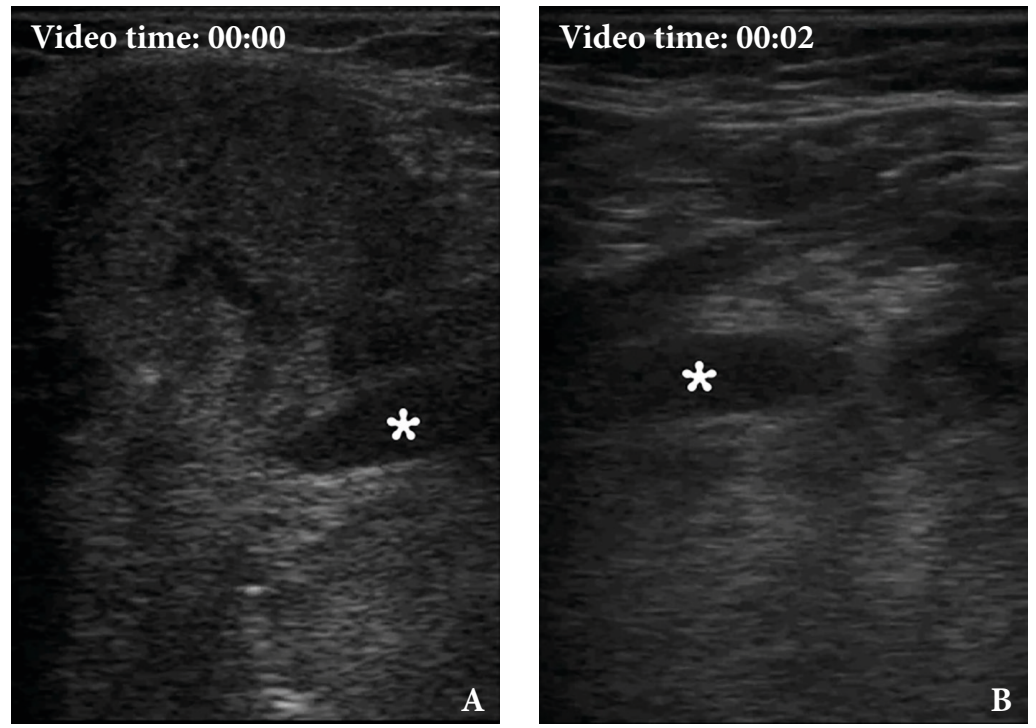

VIDEO. Supplemental Video Content $(\mathbf{A}, \mathbf{B})$ demonstrates the gray scale ultrasound examination of the right inflamed submandibular gland with a sialolith and mucus plug in its dilated Wharton 's duct filled with anechoic fluid (ie, suppurated saliva) (asterisk). Video is available in the page of the full-text article on dtjournal.org and in the YouTube channel 'Videos DTJournal', available at https://youtu.be/NF5MY60W3BQ.

Total video `s duration: 10 sec.

\section{回据回 . \\ .}

QR code leads to that video at

DTJournal's YouTube channel Videos DTJournal 


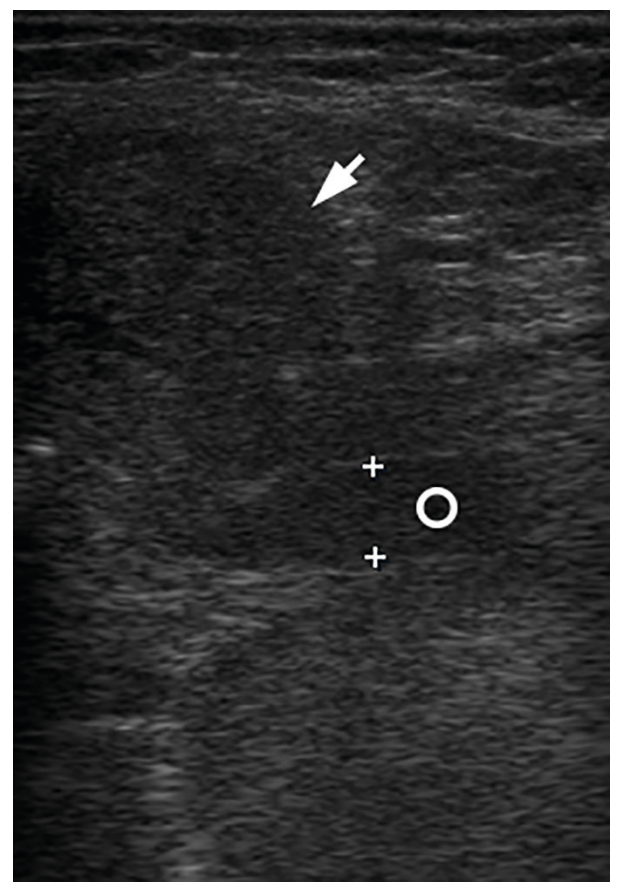

FIGURE 5. Gray scale ultrasonogram shows a right submandibular gland (arrow) and a posterior (proximal) part of the Wharton 's duct (circle) filled with anechoic content (suppurated saliva). A significant dilatation of the duct is noted. Distance between ' + ' calipers (width of the dilated duct) is $0.51 \mathrm{~cm}$.

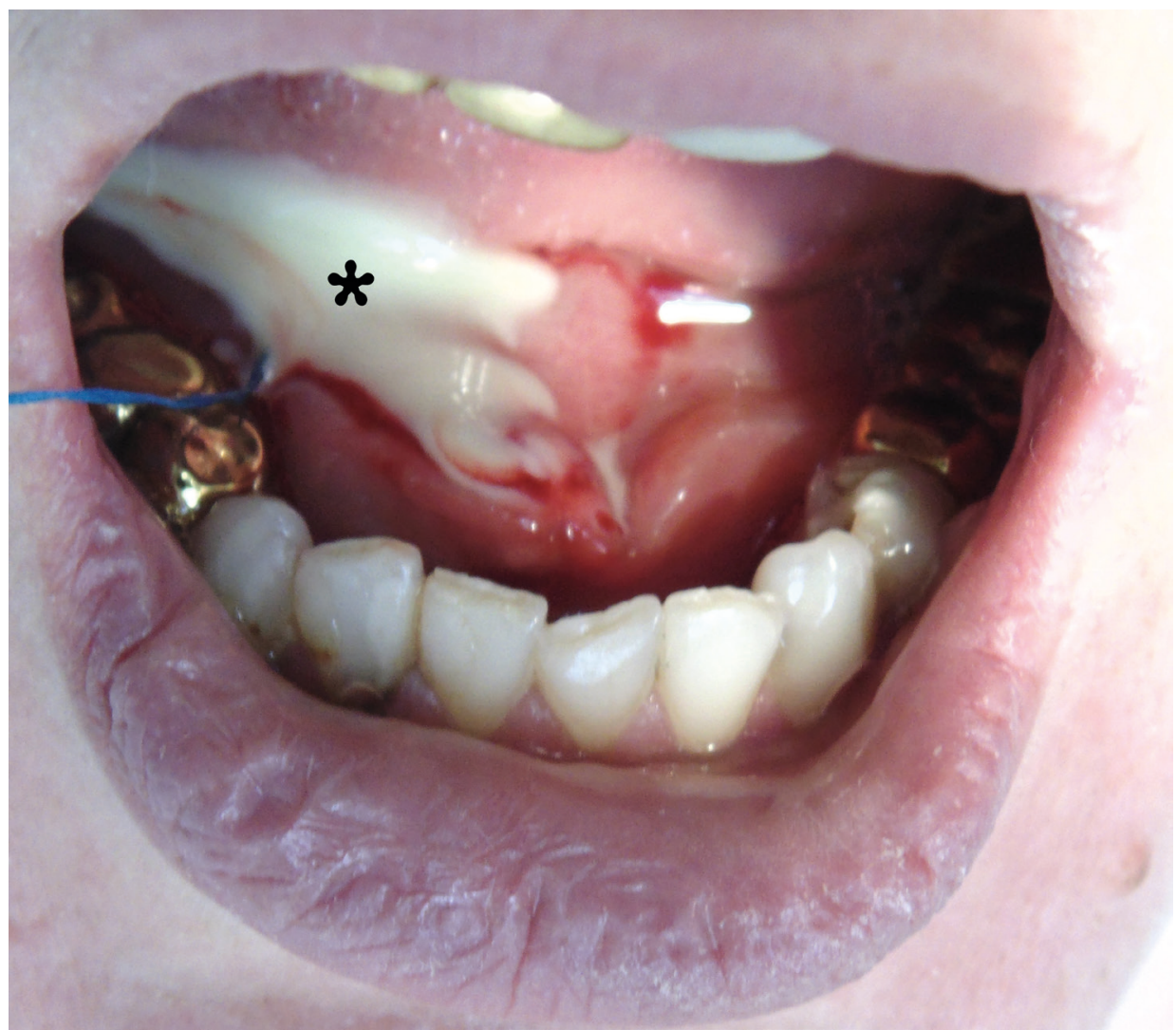

FIGURE 6. Intraoral view immediately after lancing of the Wharton `s duct. After the duct lancing a significant amount of suppurated saliva (asterisk) was obtained. 


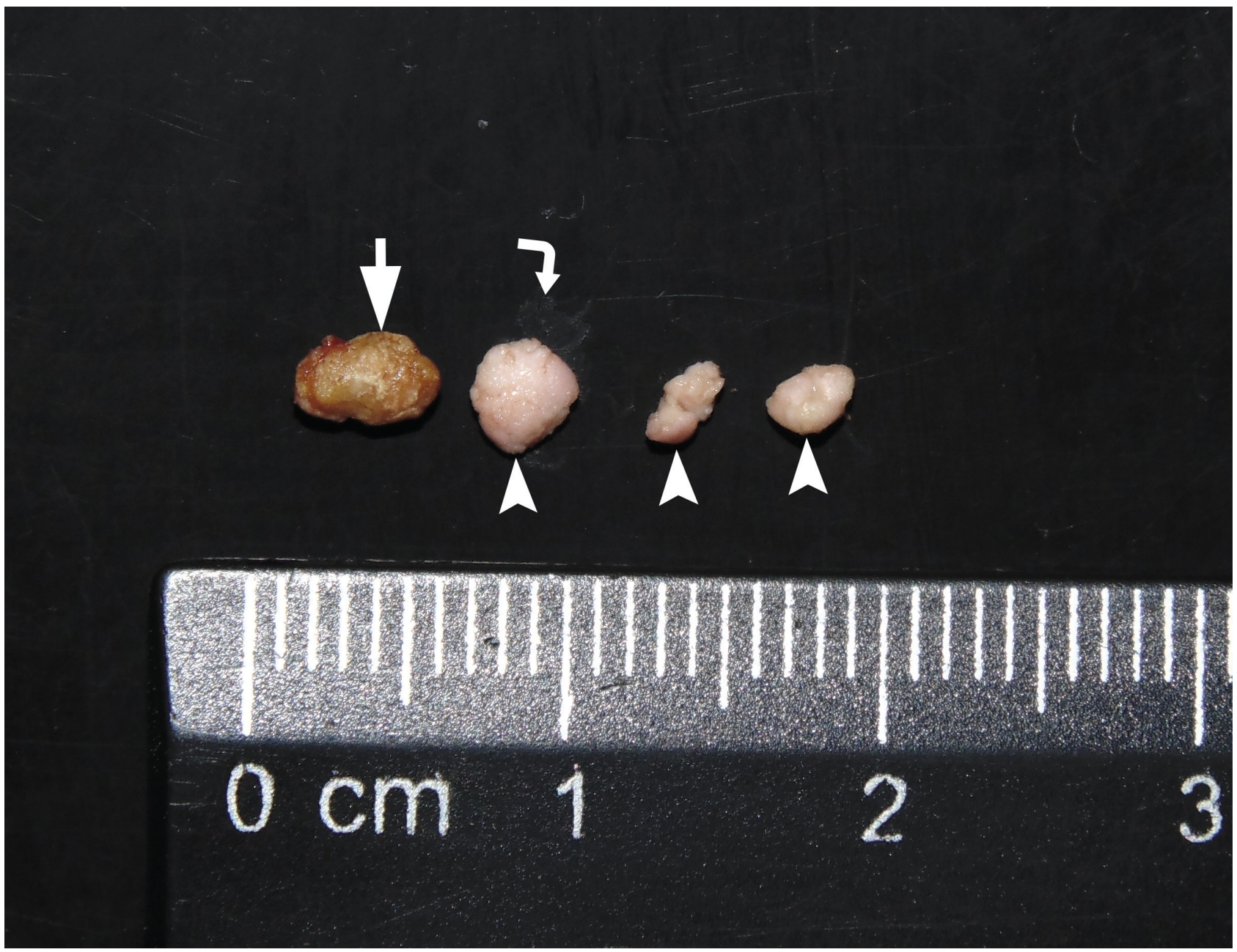

FIGURE 7. Sialolith (arrow) and three mucus plugs (arrowheads), which were received with suppurated saliva from the Wharton `s duct after its lancing. Special feature of the mucus plugs was a buttery consistency of the last. That was proved by palpation (they are easily crushed) and even upon the contact with some surface (the plugs leave smeared trace). A smeared trace from a plug is indicated by curved arrow.

\section{DISCUSSION}

Terraz et al indicated that secondary infection, due to obstruction of salivary flow by a sialoliths, is leading to progressive parenchymal inflammation, atrophy, and fibrosis of the gland..$^{14}$ The obstructive salivary gland disease with a changes in a gland tissue due to sialoliths in Ukraine is also termed as chronic sialolithic disease of the submandibular gland (synonyms: chronic calculous submaxillitis and chronic concrementous submaxillitis). ${ }^{9}$ Thomas et al found in sixty-eight patients that sensitivity and specificity of ultrasound in detection of salivary stones were 65 and $80 \%$. That was lower than sensitivity (98 percent) and specificity (88 percent) for $\mathrm{CT}^{20}$
One of the main ultrasound features of the sialoliths is an artifact of acoustic shadowing (synonym:posterior acoustic shadowing ${ }^{21}$ ). Generally, this artifact may appear behind bones, stones, metal inclusions, gas, etc. as 1) clean (synonyms: complete ${ }^{22}$ and total), 2) partial, or 3) dirty shadowing, what we can see at Table $2 .{ }^{23,24}$ But in case of sialolithiasis the shadowing is typically presented as clean or partial, depending on the calcification`s size.

\section{LOCATIONS OF THE STONES AND PLUGS}

Erkul and Gillespie used the useful location's classification for the salivary duct scar location. ${ }^{25}$ We used that location's classification for describing the precise place of the intraductal bodies of the 
submandibular gland, such as stones and plugs:

1. Ostium (orifice of the duct is opened in area of sublingual caruncle).

2. Distal part of the main duct-part of the Wharton's duct close to the duct's ostium (a synonym according to Thomas et al is 'anterior Wharton`s duct ${ }^{20}$ ).

3. Proximal part of the main duct-part of the Wharton's duct close to the gland (a synonym according to Turner is 'posterior duct'26).

4. Hilum-part of the Wharton's duct which enters the submandibular gland.

5. Intraglandular duct.

\section{SUMANDIBULAR GLAND: ULTRASOUND FEATURES}

According to Ching and Ahuja the nonsymptomatic submandibular gland is a well-capsulated structure which has a uniform homogenous parenchymal echo pattern. ${ }^{22}$ Also, the authors stated that the swollen gland due to sialoliths or other obstructive reason may become heterogeneously hypoechoic and may show dilatation of the intraglandular ductal system. ${ }^{22}$

\section{WHARTON 'S DUCT: ULTRASOUND FEATURES}

The length of the Wharton's duct according to Ching and Ahuja varies but is approximately one and a half times the axial length of the submandibular gland. ${ }^{22}$ Carlson and Ord have noticed in their textbook "Salivary Gland Pathology: Diagnosis and Management" that submandibular duct is about 5 $\mathrm{cm}$ long in the adult. ${ }^{19}$

In normal (nonsymptomatic) cases the Wharton 's duct can be seen only occasionally. ${ }^{27}$ It will be seen as a hypoechoic linear structure with a thin echogenic wall. ${ }^{21,22}$ In case of obstructive salivary gland disease or sialodochitis ${ }^{28}$ the duct will be dilated and filled with anechoic fluid.

\section{SALIVARY STONES: ULTRASOUND FEATURES}

Gritzmann and Katz et al described a sialolith at sonogram as a bright curvilinear echo complex with posterior shadowing..$^{29,28}$ Ching and Ahuja reported that calculus at sonograms has an echogenic rim with complete posterior acoustic shadowing. ${ }^{22}$ Goncalves et al clearly noted the salivary stones on ultrasound shows as hyperechoic reflexes with distal signal loss. ${ }^{8}$ Aiyekomogbon et al stated that sialolith is usually visualized as a brightly echogenic mass casting posterior acoustic shadow. ${ }^{15}$ But some authors insist that in sialoliths smaller than $2 \mathrm{~mm}$, this shadow may be missing. ${ }^{28}$

\section{MUCUS PLUGS: ULTRASOUND FEATURES}

According to our case the plug has an isoechoic pattern with no acoustic shadowing behind.

Taking into account the fact that during the

TABLE 1. Comparison of Ultrasound Features of the Sialolith and Mucus Plug Located in the Wharton's Duct According to Presented Case.

\begin{tabular}{|c|c|c|}
\hline Ultrasound Features & Sialolith & Mucus Plug \\
\hline Echogenicity & Hyperechoic & Isoechoic \\
\hline Artifact of acoustic shadowing & Present & Absent \\
\hline
\end{tabular}

TABLE 2. Types of Acoustic Shadowing Artifact According to Hindi and Colleagues. ${ }^{23}$

\begin{tabular}{|c|c|c|c|}
\hline Characteristics & Clean (Total) Shadowing & Partial Shadowing & Dirty Shadowing \\
\hline $\begin{array}{c}\text { Appearance of the } \\
\text { acoustic shadowing } \\
\text { artifact }\end{array}$ & $\begin{array}{c}\text { Uniformly anechoic signal } \\
\text { behind a structure. }\end{array}$ & $\begin{array}{c}\text { Hypoechoic signal behind a a } \\
\text { structure. }\end{array}$ & $\begin{array}{c}\text { Low-level echoes in the } \\
\text { shadow deep to gas. }\end{array}$ \\
\hline In what cases occurs & $\begin{array}{c}\text { Behind stones/calcifications } \\
>0.5 \mathrm{~mm} \text {, and bones. }\end{array}$ & $\begin{array}{l}\text { 1. Behind calcifications and } \\
\text { stones }<0.5 \mathrm{~mm} .\end{array}$ \\
$\begin{array}{l}\text { 2. Behind fat containing } \\
\text { structures when surrounded } \\
\text { by other soft tissues. }\end{array}$ & Behind gas collections. \\
\hline
\end{tabular}


surgery and evacuation of the duct's content we received three plugs, all 8 sonograms and three videos were retrospectively evaluated and confirmed that two other mucus plugs were located exactly in the ostium area. After all, this was indicated by the following:

1. In addition to one plug in Wharton's duct, there were no other plugs posteriorly to the calculus.

2. Concrement and concomitant posterior plug were located in the middle part of the duct, which created a place for possible localization of the two other plugs in the anterior duct.

3. The presence of two unclear objects in the anterior duct close to ostium.

And a thesis of Ching and Ahuja, that "stone impacted at the ductal ostium (30 percent) may not be well depicted on sonography, but many cases (65\%) have associated main duct dilatation" ${ }^{22}$ can explain why we cannot precisely detect other two mucus plugs, as they were located close to the ductal ostium.

\section{CONCLUSIONS}

Thus, a first report of the precise ultrasound and clinical appearance of the mucus plugs and sialolith is presented. Also, a 10 seconds supplemental video is added. Comparison of the gray scale and color Doppler ultrasound images of the obstructed submandibular gland with nonsymptomatic contralateral organ is showed.

In addition, to our humble opinion, the mucus plugs which were presented at the ultrasound and post op images can clearly support the arguments of one of the theories, that sialolith 's formation is happened by deposition of calcium salts around a nidus of organic material-mucus plug. ${ }^{7,} 30$ So, in that case, mucus plugs can be clearly considered as a stage in the formation of salivary stones. And in that case the usage of ultrasonography can be helpful both in the detection of stones and plugs.

\section{TERM OF CONSENT}

Written patient consent was obtained from a lady to publish the clinical photographs.

\section{CONFLICT OF INTEREST}

The authors declare no conflict of interest.

\section{ROLE OF THE AUTHORS}

The authors are equally contributed to that paper.

\section{FUNDINGS}

No funding was received for this study.

\section{ACKNOWLEDGMENTS}

None.

\section{REFERENCES}

1. Chuangqi Y, Chi Y, Lingyan Z. Sialendoscopic findings in patients with obstructive sialadenitis: long-term experience. Br J Oral Maxillofac Surg 2013;51:337-41. https://doi.org/10.1016/j.bjoms.2012.07.013.

2. Scully C. Oral and maxillofacial medicine: the basis of diagnosis and treatment. 3rd ed. London: Churchill Livingstone; 2013.

3. Fernandes RP, Salman S, Quimby A. Minimally invasive techniques for management of salivary gland pathology. J Diagn Treat Oral Maxillofac Pathol 2017;1:11-4. https://dx.doi.org/10.23999/j. dtomp.2017.1.2.

4. Sharav Y, Benoliel R. Orofacial pain and headache. 1st ed. Maryland Heights: Mosby; 2008.

5. Capaccio P, Torretta S, Ottaviani F, Sambataro G, Pignataro L. Modern management of obstructive salivary diseases. Acta Otorhinolaryngol Ital 2007;27:161-72.

6. Rana SS, Arya S. Sialolithiasis of the Wharton's duct report of 3 cases. J Adv Med Dent Scie Res 2017;5:10811. https://doi.org/10.21276/jamdsr.2017.5.11.27.

7. Al-Abri R, Marchal F. New era of endoscopic approach for sialolithiasis: sialendoscopy. Sultan Qaboos Univ Med J 2010;10:382-7.

8. Goncalves $M$, Schapher $M$, Iro $H$, Wuest $W$, Mantsopoulos K, Koch M. Value of sonography in the diagnosis of sialolithiasis: comparison with the reference standard of direct stone identification. J Ultrasound Med 2017;36:2227-35. https://doi. org/10.1002/jum.14255.

9. Tymofieiev OO. Manual of maxillofacial and oral surgery [Russian]. 5th ed. Kyiv: Chervona Ruta-Turs; 2012. 
10. Carta F, Farneti P, Cantore S, Macrì G, Chuchueva N, Cuffaro L, Pasquini E, Puxeddu R. Sialendoscopy for salivary stones: principles, technical skills and therapeutic experience. Acta Otorhinolaryngol Ital 2017;37(2):102-12. https://dx.doi. org/10.14639/0392-100X-1599.

11. Pace CG, Hwang K-G, Papadaki M, Troulis MJ. J Oral Maxillofac Surg 2014;72:2157-66. https://doi. org/10.1016/j.joms.2014.06.438ю.

12. Larheim TA, Westesson P-L. Maxillofacial imaging. 1st ed. Berlin: Springer-Verlag, 2006.

13. Rzymska-Grala I, Stopa Z, Grala B, Gołębiowski M, Wanyura H, Zuchowska A, Sawicka M, Zmorzyński M. Salivary gland calculi - contemporary methods of imaging. Pol J Radiol 2010;75:25-37.

14. Terraz S, Poletti PA, Dulguerov P, Dfouni N, Becker CD, Marchal F, Becker M. How reliable is sonography in the assessment of sialolithiasis? AJR Am J Roentgenol 2013;201:W104-9. https://doi. org/10.2214/AJR.12.9383.

15. Aiyekomogbon JO, Babatunde LB, Salam AJ. Submandibular sialolithiasis: the roles of radiology in its diagnosis and treatment. Ann Afr Med 2018;17:2214. https://doi.org/10.4103/aam.aam_64_17.

16. Prendes BL, Orloff LA, Eisele DW. Therapeutic sialendoscopy for the management of radioiodine sialadenitis. Arch Otolaryngol Head Neck Surg 2012;138:15-9. https://doi.org/10.1001/ archoto.2011.215.

17. Marchal F, Kurt AM, Dulguerov P, Lehmann W. Retrograde theory in sialolithiasis formation. Arch Otolaryngol Head Neck Surg 2001;127(1):66-8.

18. Buckenham T. Salivary duct intervention. Semin Intervent Radiol 2004;21:143-8. https://doi. org/10.1055/s-2004-860872.

19. Carlson ER, Ord RA. Salivary gland pathology: diagnosis and management 2nd ed. Hoboken: WileyBlackwell; 2016.

20. Thomas WW, Douglas JE, Rassekh CH. Accuracy of ultrasonography and computed tomography in the evaluation of patients undergoing sialendoscopy for sialolithiasis. Otolaryngol Head Neck Surg 2017;156:834-9. https://doi. org/10.1177/0194599817696308.

21. Huang F, Caton R, Colla J. Point-of-care ultrasound diagnosis of acute sialolithiasis with sialadenitis. Clin Pract Cases Emerg Med 2017;1:437-8. https://doi. org/10.5811/cpcem.2017.7.34907.

22. Ching AS, Ahuja AT. High-resolution sonography of the submandibular space: anatomy and abnormalities. AJR Am J Roentgenol 2002;179:703-8. https://doi. org/10.2214/ajr.179.3.1790703.

23. Hindi A, Peterson C, Barr RG. Artifacts in diagnostic ultrasound. Rep Med Imag 2013; Volume 2013:29-48. https://doi.org/10.2147/RMI.S33464.

24. Baad M, Lu ZF, Reiser I, Paushter D. Clinical Significance of US artifacts. Radiographics 2017;37:1408-23. https://doi.org/10.1148/ rg.2017160175.

25. Erkul E, Gillespie MB. Sialendoscopy for non-stone disorders: the current evidence. Laryngoscope Investig Otolaryngol 2016;1:140-5. https://doi.org/10.1002/ lio2.33.

26. Turner MD. Combined surgical approaches for the removal of submandibular gland sialoliths. Atlas Oral Maxillofac Surg Clin North Am 2018;26:145-51. https://doi.org/10.1016/j.cxom.2018.05.005.

27. Ahuja AT, Evans RM. Practical head and neck ultrasound. 1st ed. London: Greenwich Media Medical Limited. 2000.

28. Katz P, Hartl DM, Guerre A. Clinical ultrasound of the salivary glands. Otolaryngol Clin North Am 2009;42:973-1000. https://doi.org/10.1016/j. otc.2009.08.009.

29. Gritzmann N. Sonography of the salivary glands. Am J Roentgenol 1989;153:161-6.

30. Ashby RA. The chemistry of sialoliths: stones and their homes. In: Norman JED, McGurk M, editors. Color Atlas and Text of the Salivary Glands. Diseases, Disorders, and Surgery. London: Mosby-Wolfe, 1995:243-251. 